\title{
Effect of Glass Spheres and Stacking Functionalization on the Properties of E Glass/Cyanate Modified Epoxy Laminate
}

\author{
W. Andrew Nallayan ${ }^{1 *}$, K. R. Vijayakumar ${ }^{2}$ and Usama Tariq Rasheed ${ }^{2}$ \\ 'Mechanical Department, St. Peter's University, Chennai - 600054, Tamil Nadu, India; wa_nallayan@yahoo.com \\ ${ }^{2}$ Mechanical Department, Dr. M. G. R. Educational and Research Institute, Chennai - 600095 Tamil Nadu, India; \\ Isjv2002@gmail.com, usamatariqr@gmail.com
}

\begin{abstract}
Objectives: The composite materials that are used for flat panel Radome in aircrafts are going through continuous up-gradation in an attempt to enhance their performance with extended capabilities against severe environments. The addition of glass microspheres as fillers in cross plied laminates has been done here, with an intention of measuring the extent of its influence in the selected critical mechanical/structural and di electrical properties. Methods: The thin laminates with three and four plies oriented in 0/90-degree order respectively were fabricated by hand lay technique. Using ASTM standards, the samples were cut by water jet cutting and properties like tensile strength, flexural strength, di electrical strength; loss tangent (Dissipation factor) and dielectric constant were latter evaluated. The inter relation between stacking sequences in accordance with unbalanced and balanced nature of three and four plied laminates respectively and the significance of glass fillers in influencing the above properties are the objectives that were projected into the findings. Findings: Apparently, a better structural response to the loading condition was observed in thicker and symmetrically balanced four plied laminates with $10 \%$ filler, wherein di electric constant and loss tangent were found to be best for thinner three plied laminates with $10 \%$ and $30 \%$ fillers respectively. Di electric strength was found to be superior for thinner three plied laminates but with $20 \%$ filler addition. The conclusive summary captures the significant role played by the glass microspheres as fillers in influencing the different properties under different testing conditions. Improvements: Besides the glass microspheres the other filler materials with different tradeoffs between di electrical and mechanical/structural properties could be tried to capture the property changes in the offing. Further novelty could be brought in to this spectrum by introducing variations with regard to the ply numbers and their orientations while stacking the plies to build laminates.
\end{abstract}

Keywords: Cross Plied Laminates, Glass Spheres, Modified Epoxy, Properties of Epoxy/Cyanate, Stacking Functionalization

\section{Introduction}

The epoxy resin is the most widely used matrix material for many structural composites. It has many good properties like high stiffness, low shrinkage, good adhesion to glass, carbon fiber etc. Unfortunately, the very factor contributing to its high stiffness and heat resistance leads to its main drawback i.e. lack of toughness. Hence, among the different materials used for the modification of epoxy resins, cyanate esters are expected to be the best material to improve the thermo-mechanical properties. Cyanate esters also offer ease of handling and processing similar to that of epoxy resin systems. Thus, blending of epoxy with cyanate ester resin continues to attract research interest in order to impart improvements in fracture toughness without compromising of other mechanical and thermal properties. Never a single choice of material could possibly possess both these properties at its best.

${ }^{*}$ Author for correspondence 
Hence, compromises are often made with an intention of selecting the best combination with regard to a potential application. Since the late seventies, varieties of methodologies have been tried to improve the toughening of epoxy resin systems $\mathrm{s}^{1-3}$. Addition of many inorganic materials like glass beads was proven to improve the toughness of the epoxy systems $\frac{4-5}{}$. The toughening mechanisms out of adding rigid micro particles may be due to factors like crack deflection, crack pinning, particle deboning and micro shear bonding of the matrix ${ }^{6-9}$. Blending of Cyanate ester and epoxy has gained lots of research potential in the past decades due to the advance structural requirements in the field of aerospace and electronics ${ }^{10-12}$ often, these fields require composites of high strength and good di electrical properties. Many researchers have done variety of work to predict the influence of fillers like micro glass spheres with a small aspect ratio on the various mechanical properties of composites.

In order to study the influence of glass microspheres as filler on the properties of the laminates, the filler percentages were varied in the laminates. With an intention of exploiting the chosen structural properties along with an eye to prevent the transmission signals from getting blocked across the laminates, the investigational scope here has been limited to thin laminates with simple 0/90/0/90 orientations as applicable to 3 and 4 plied laminates. This will further enable one to assess the influence of laminate symmetricity over the properties, under investigation.

Thus, cyanate ester modified epoxy resin as a matrix material and 1200 GSM E Glass unidirectional fabric for reinforcement which is used here with solid micro glass spheres as a filler material, the latter being mainly added to improve the di electrical properties of the laminate. The 15\% Cyanate ester loaded epoxy resin and 1200 GSM E Glass Unidirectional fiber were chosen as matrix and reinforcement respectively for fabricating 2 and 3 cross plied laminates with $0 / 90 / 0 / 90$ orientations. Thus to summarize, this work focuses on the functionalization of the laminate in terms of blending of epoxy with cyanate, addition of fillers and incorporating simple stacking variances.

Obviously, the need for developing such materials has gained lot of momentum only recently. Only few people have worked to see the influence of ply thickness variations/stacking sequences with respect to the properties of the laminates like tensile, flexural strength and their respective moduli. But not much work is done to explore the inter influence of mechanical, di electrical properties with respect to glass fillers and stacking variations. Hence, apart from generally predicted mechanical properties the di electrical properties like di electric strength, di electric constant and dissipation factors were also taken into consideration with the focus on establishing best tradeoff between mechanical/structural and di-electrical performances.

\section{Materials and Methods}

\subsection{Materials}

Epoxy resin, Curing agent and unidirectional fibers of 1200 GSM were procured from Sackthi fibers, Chennai, India and Bisphenol A Cyanate ester was imported from Shanghai Righton, Shanghai, China. Glass spheres ${ }^{9-12}$ (micrometers diameter) were imported from SigmaAldrich, USA as shown in Figure 1(a) and 1(b).

Curing agent/Hardener (Tetra-ethylene-amine), was optimized with regard to Cyanate Ester (BACY) modified Epoxy resin (Di-glycidyl-ether of bisphenol A/DGEBA) as shown in Figure 2(a) to 2(h). Optimization was done by varying the form, state and quantity of the curing agent. Through a number of trials we arrived at a defect free cured resin mixture. Before the optimization was achieved defects like continuous foaming with sponginess in the cured blend, presence of glassy pin holes of varying sizes inside, open blow holes on the cured surface and presence of partially trapped undissolved cyanate were observed visually. Addition of a sub optimal curing agent and out of accelerated exothermic reaction due to the addition of hardener (specifically in forms like talc and molten state) lead to a faster gelation of the blend thus reducing the potable time of the matrix blend. Good potting period of around 15 to 30 minutes with almost zero defects was observed when $25.33 \%$ of the curing agent was mixed and later added to the blend of Cyanate Ester / Epoxy resin mix and allowed to cure. Few of the cured samples are shown in Figure 2(h), with the last frame showing cured resin with almost no defects.

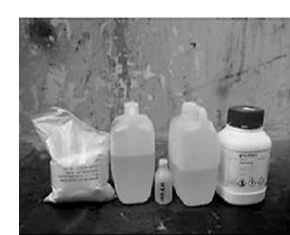

(a)

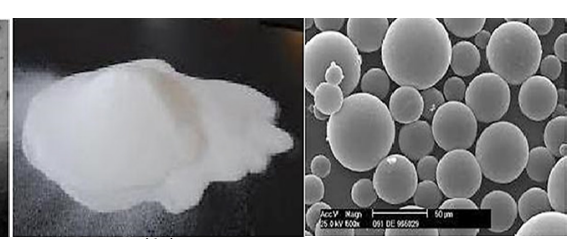

(b) (c)
Figure 1. (a) Ingredients, (b) Solid glass spheres, (c) Glass spheres under SEM. 


\subsection{Methods and Testing}

The composite laminates were fabricated from E-glass fiber (Unidirectional $1200 \mathrm{GSM}$ ) and cyanate modified epoxy resin by hand-lay technique. The addition of hardener (tri-ethylene tetra-amine) was based on optimized value as stated above through number of trials. The cyanate loading was fixed at $15 \%$ by weight of epoxy resin. The mixture of resin and cyanate ester was stirred for ensuring uniform dispersion of cyanate ester, followed by the addition of tetra-ethylenetri-amine (hardener/curing agent) in $25.33 \%$ by weight of epoxy and stirred for around 20 minutes. Mylar sheet coated with stonewash polish as a release agent was further applied with a layer of resin using a brush. Then the first layer of the fiber $(300 \times 300 \mathrm{~mm})$ was placed on the resin and consolidated using rollers. This process was repeated to consolidate 3 and 4 cross plied laminates, namely L1 to L9.L1 was fabricated with neat epoxy with 3 plied cross plied configuration taking necessary precautions to keep the fabric well aligned. The fabricated sheets were then cured at room temperature for around 8 hours and latter cut into samples as per the ASTM Stds., as shown in Figure 3(a), 3(b) and Figure 4(a), 4(b). Glass microspheres amounting to $10 \%, 20 \%$ and $30 \%$ as fillers were added to the 3 plied laminates viz. L3 to L5 and in 4 plied laminate viz. L6 and L9 respectively. L2 and L6 were the ones with $0 \%$ filler. The notations of the various cyanate modified epoxy glass fiber composites are presented in Table 1.

The Universal Testing Machine (UTM) at the Scientific Engineering Works, New Delhi was used with a maximum testing load rate of 5 ton with a digital encoder. The software created by FIE was used for performing the tests. The test specimens were positioned suitably in various grips of the testing machine. The grips were tightened evenly and firmly to prevent any slippage. The speed of testing was set at the proper rate and the machine was started. Different types of loading were subjected on the specimen to figure out the tensile and flexural strength. A tensile specimen as per the standardized sample crosssection given by ASTM: D638 was implicated. It has two shoulders and a gauge (section) in between; the shoulders are large so they can be readily gripped.

The flexural strength represents the highest stress experienced within the material at its moment of rupture. For electrical testing the samples were cut using ASTM D149. The important tested di electrical properties are di electric strength, di electric constant and Loss Tangent/ dissipation factor. The di electric strength is

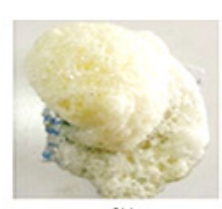

(a)

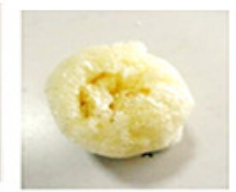

(b)

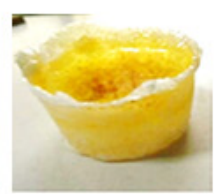

(c)

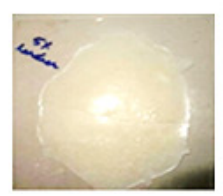

(d)

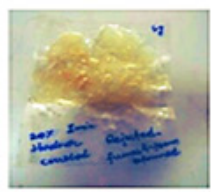

(e)

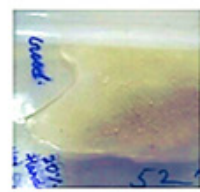

(f)

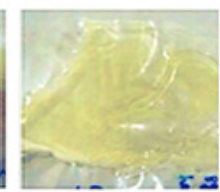

(g)

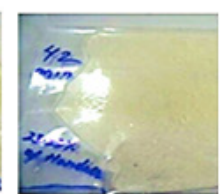

(h)

Figure 2. Hardener/curing agent optimization, (a) Foamed samples during hardener Optimization in confined cup (Hardener mixed/Un Optimized Quantity in talc form, (b) Foamed samples during hardener Optimization in confined cup (Hardener/Un Optimized Quantity mixed in talc form), (c) Cured samples with pinholes in confined cup (Hardener/Unoptimized Quantity mixed in granules form), (d) Curing of sample in an increased surface area (Hardener/Unoptimized Quantity mixed in molten form), (e) Curing of sample in an increased surface area (Hardener/Unoptimized Quantity mixed in granules form), (f) Curing of sample in an increased surface area (Hardener/Unoptimized Quantity mixed in granules form), (g) Curing of sample in an increased surface area (Hardener/Unoptimized Quantity in talc form), (h) Curing of sample in an increased surface area (Hardener/Optimized Quantity, i.e. 25.33\% \& in talc form).

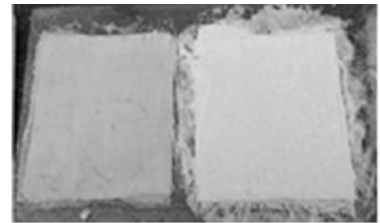

(a)

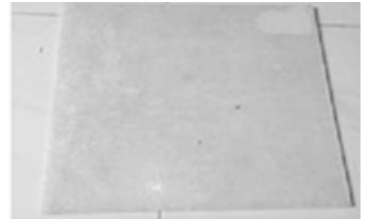

(b)

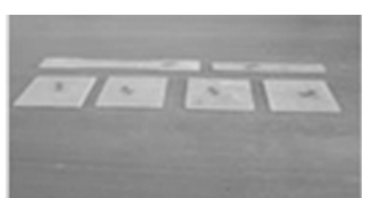

(a)

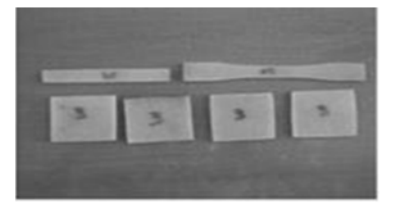

(b)

Figure 3. (a) Laminate during processing under Hand Lay Technique, (b) Cured laminate under Hand Lay Technique.

Figure 4. (a) Few cut samples/4 plied, (b) Few cut samples/3 plied. 
Table 1. Laminate coding details

\begin{tabular}{|c|c|c|}
\hline S. No. & Name & Description \\
\hline 1. & EP-L1 & 3 Plies + Epoxy 100g + Hardener 25.33\% + Cyanate Ester 0\% + Filler 0\% \\
\hline 2. & EPCY-L2 & 3 Piles + Epoxy 100g + Hardener $25.33 \%+$ Cyanate Ester $15 \%+$ Filler $0 \%$ \\
\hline 3. & EPCY10F-L3 & 3 Piles + Epoxy $100 \mathrm{~g}+$ Hardener $25.33 \%+$ Cyanate Ester $15 \%+$ Filler $10 \%$ \\
\hline 4. & EPCY20F-L4 & 3 Piles + Epoxy 100g + Hardener $25.33 \%+$ Cyanate Ester $15 \%+$ Filler $20 \%$ \\
\hline 5. & EPCY30F-L5 & 3Piles + Epoxy 100g + Hardener 25.33\% + Cyanate Ester 15\% + Filler 30\% \\
\hline 6. & EPCY-L6 & 4Piles + Epoxy 100g + Hardener $25.33 \%+$ Cyanate Ester $15 \%+$ Filler $0 \%$ \\
\hline 7. & EPCY10F-L7 & 4Piles + Epoxy 100g + Hardener $25.33 \%+$ Cyanate Ester $15 \%+$ Filler $10 \%$ \\
\hline 8. & EPCY20F-L8 & 4 Piles + Epoxy 100g + Hardener $25.33 \%+$ Cyanate Ester $15 \%+$ Filler $20 \%$ \\
\hline 9. & EPCY30F-L9 & 4 Piles + Epoxy 100g + Hardener 25.33\% + Cyanate Ester 15\% + Filler 30\% \\
\hline
\end{tabular}

the maximum working voltage a material can withstand without breaking down, i.e. without experiencing failure of its insulating properties. At breakdown, the electric field frees bound electrons, turning the material into a conductor. The field strength at which breakdown occurs in a given case is dependent on the respective geometries of the di electric (insulator) and the electrodes with which the electric field is applied, as well as the rate of increase at which the electric field is applied.

Di electric strength is usually expressed as a voltage gradient (such as volts per $\mathrm{mm}$ ). The di electric loss tangent can be defined by the angle between capacitor's impedance vector and the negative reactive axis. It determines the loss line of the medium. Similar to di electric constant, low loss tangent result in "fast" subtraction while large loss tangent result in "slow" subtraction of transmitted signals. It is observed the exact values can vary greatly, depending on the particular manufacture's processes, so we should seek out the data from the manufacture for critical applications.

\section{Results and Discussions}

The mechanical behavior of a composite is so complex that, the feasibility of a proper modeling is always questionable. The experimental approach may be the only acceptable solution. Our knowledge about the special nature of composite behavior has been derived from experimental observations. The measurement of the mechanical properties is also an important element of quality control and quality assurance process, associated with the manufacture of composite material. The experimental values of tensile and flexural stress versus strain for composite specimens were determined during the tensile testing. In general, it is observed that the cyanate modified epoxy has better tensile, flexural strength and modulus invariably when compared to neat epoxy based composite which has been proved with respect to the experimental investigations. Further, the addition of fillers up to $10 \%$ of the laminate has found to increase the tensile strength, flexural strength and their respective modulus with further additions beyond $10 \%$, it shows a reverse trend. This trend is observed both in 3 plied and 4 plied laminates. The above discussed trends and comparisons have been plotted in various Figure 5(a) to Figure 5(h) and in Table 2.

The higher tensile properties are due to rigid aromatic structure and rigid triazne ring formed as a result of trimeritative reaction. Also, it was found that relatively higher tensile strengths were observed in the laminate with more number of plies, i.e. 4 plied laminate. This obviously resulted due to better bonding and adhesion characteristics between the various plies of the laminate as it has a larger fiber contact area and also due to the higher GSM of the material. It has also been observed that the addition of fillers beyond $10 \%$ in the same laminates has brought down the strength drastically. The initial surge in the values was attributed to the effect of densification of the matrix and the latter drop is attributed to the presence of fillers, similar to the presence of voids and pores in isotropic materials which act as stress raisers during the loading processes. Under the influence of external loading, the bonding in the vicinity of the fillers gets broken, which in turn initiates the process of nucleation of micro cracks. This tends to grow into macro cracks in the latter stages of loading, finally, resulting in the failure under a relatively lesser load itself. 


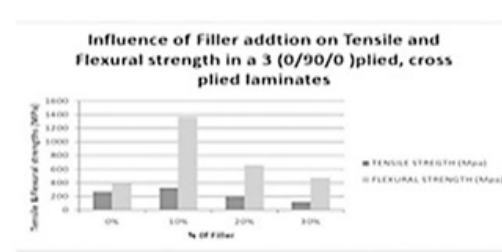

$5(a)$

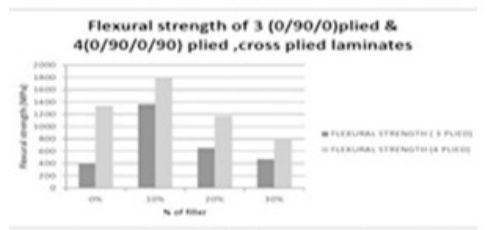

$5(d)$

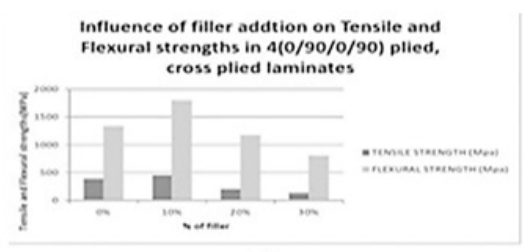

5(b)

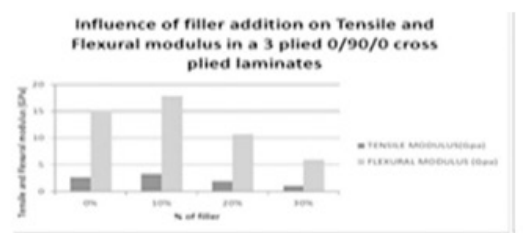

$5(\mathrm{e})$

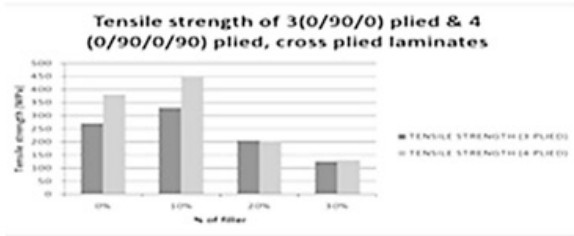

$5(\mathrm{c})$

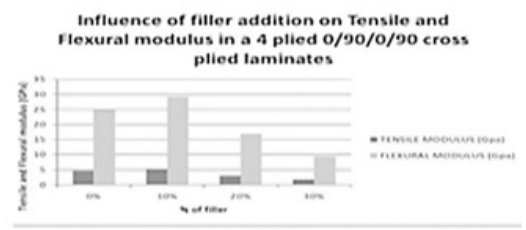

$5(f)$

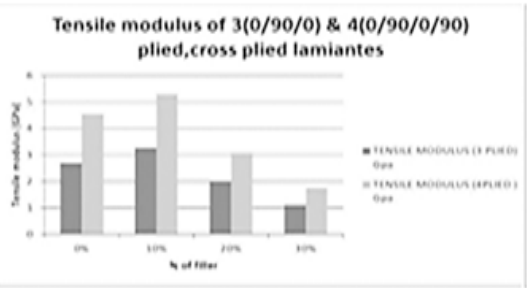

$5(\mathrm{~g})$

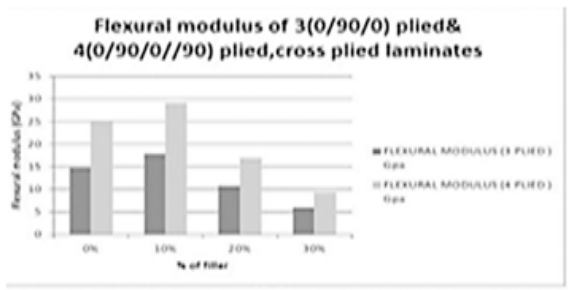

$5(\mathrm{~h})$

Figure 5. (a) Influence of Filler addition on tensile and flexural strengths in a 3 plied (0/90/0) cross laminates, (b) Influence of Filler addition on tensile and flexural strengths in a 4 plied (0/90/0) cross laminates, (c) Tensile strengths in a 3 plied (0/90/0) and 4plied (0/90/0) cross laminates, (d) Flexural strengths in a 3 plied (0/90/0)and 4plied (0/90/0) cross laminates, (e) Influence of Filler addition on tensile and flexural Modulus in a 3 plied (0/90/0) cross laminates, (f) Influence of Filler addition on tensile and flexural Modulus in a 4 plied (0/90/0) cross laminates, (g) Tensile modulus in a 3 plied (0/90/0)and 4 plied $(0 / 90 / 0)$ cross laminates, (h) Flexural modulus in a 3 plied (0/90/0) and 4 plied (0/90/0) cross laminates.

Table 2. Mechanical/structural properties

\begin{tabular}{|c|c|c|c|c|}
\hline $\begin{array}{c}\text { Test } \\
\text { Specimen }\end{array}$ & $\begin{array}{c}\text { Tensile } \\
\text { Strength } \\
\text { Mpa }\end{array}$ & $\begin{array}{c}\text { Tensile } \\
\text { Modulus } \\
\text { Gpa }\end{array}$ & $\begin{array}{c}\text { Flexural } \\
\text { Strength } \\
\text { Mpa }\end{array}$ & $\begin{array}{c}\text { Flexural } \\
\text { Modulus } \\
\text { Gpa }\end{array}$ \\
\hline L1 & 251 & 2.6 & 333 & 7.9 \\
\hline L2 & 271 & 2.68 & 390 & 14.7 \\
\hline L3 & 330 & 3.25 & 1365 & 17.82 \\
\hline L4 & 205 & 1.95 & 655 & 10.68 \\
\hline L5 & 125 & 1.1 & 467 & 5.93 \\
\hline L6 & 381 & 4.53 & 1335 & 24.83 \\
\hline L7 & 446 & 5.30 & 1880 & 29.05 \\
\hline L8 & 201 & 3.08 & 1170 & 16.88 \\
\hline L9 & 131 & 1.7 & 800 & 9.27 \\
\hline
\end{tabular}

- Similar trend was also observed in the values of flexural strength and the substantial increase in the flexural strength, after cyanate loading was also observed. This is due to the formation of a network structure between cyanate ester and the epoxy matrix. The marginal variations in the above properties might be also attributed to other factors like the purity of the cyanate ester and also due to the fabrication accuracy.

- Electrical properties like di electric Constant and di electric strength by and large reflect ability of the laminate to transmit the RF signals through it with minimum attenuation or rather without any communication failure. Any noticeable loss here would mean communication failure between the Radar and the target. It is known that a higher Di Electric strength and lower Di Electric constant with lower Loss Tangent/ Dissipation factor are the requirement for the Radome wall, irrespective of the frequency against which it is tuned. The various interpretations out of the Di Electrical tests have been plotted in Figures: 6(a) to 6(c) and tabulated in Table 3. From the tests and results it could be observed that best value for Di Electric strength was observed for 3 plied laminate with $10 \%$ 


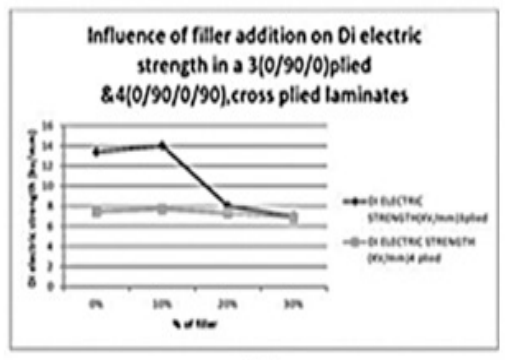

(a)

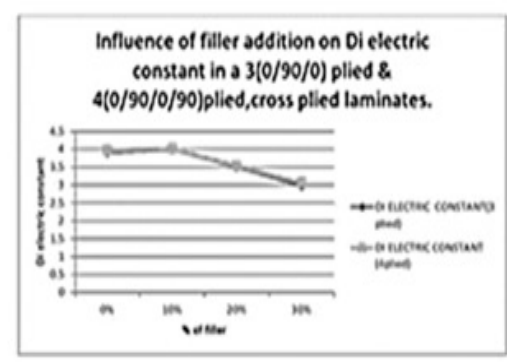

(b)

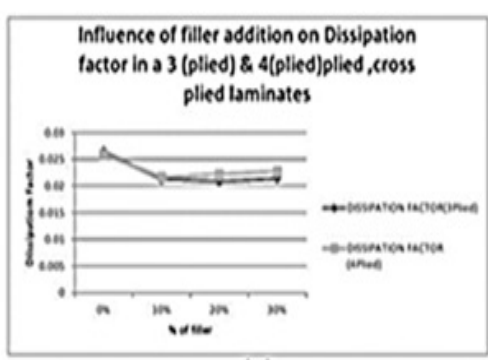

(c)

Figure 6. (a) Influence of Filler on di electric strength in 3 plied (0/90/0) and 4 plied (0/90/0) cross laminates, (b) Influence of Filler on di electric Constant in 3 plied (0/90/0) and 4 plied (0/90/0) cross laminates, (c) Influence of Filler on di electric Factor in 3 plied (0/90/0) and 4plied (0/90/0) cross laminates.

Table 3. Di Electrical properties

\begin{tabular}{|c|c|c|c|}
\hline $\begin{array}{c}\text { Test } \\
\text { Specimen }\end{array}$ & $\begin{array}{c}\text { Di Electric } \\
\text { Strength }\end{array}$ & $\begin{array}{c}\text { Di Electric } \\
\text { Constant }\end{array}$ & $\begin{array}{c}\text { Dissipation } \\
\text { Factor }\end{array}$ \\
\hline L1 & 16 & 8.1 & 0.061 \\
\hline L2 & 7.72 & 3.91 & 0.0264 \\
\hline L3 & 13.38 & 4.01 & 0.0213 \\
\hline L4 & 6.27 & 3.511 & 0.0209 \\
\hline L5 & 7 & 2.98 & 0.0214 \\
\hline L6 & 7.46 & 3.98 & 0.0259 \\
\hline L7 & 7.72 & 4.02 & 0.0217 \\
\hline L8 & 7.32 & 3.55 & 0.0222 \\
\hline L9 & 6.83 & 3.08 & 0.0227 \\
\hline
\end{tabular}

filler addition. Lowest Di Electric constant was found for laminates with $30 \%$ filler addition in both 3 and 4 plied laminates.

Loss tangent or Dissipation factor, a property that reflects the Ohmic losses or rather power losses in the laminate was found to be seen least in 3 plied laminate with $20 \%$ addition of fillers. This has proved the role of filler in influencing Di Electric properties in one way or the other. Di Electric strength, a factor known to be influenced by the wall thickness besides the fillers have been also observed here with the thinnest wall offering highest Di Electric strength. Thus all the test results shows a favorable inclination towards the expected trend and further scope on the same line could be further ascertained by further controlling the experimental parameters during the fabrication of the laminates and during the testing procedures. The quality of the ingredients could also have a strong say in the final outcome.

\section{Conclusion}

It has been found that the tensile and flexural strength with their respective moduli have shown an increasing trend, both in 3 and 4 plied cross ply laminates loaded with $10 \%$ of glass microspheres as filler. The values show a decreasing trend beyond $10 \%$ filler addition. Though the glass fillers have been added here, mainly to enhance the electrical aspects due to its good Di Electrical properties, which it demonstrates here, the mechanical strengths viz. tensile and flexural increases initially and then decline later with respect to $10 \%$ filler addition. This is due to the fact, fillers when initially added to the resin till $10 \%$ by volume, fill up the void spaces effectively, and during the curing process thereby, improving the resistance against the tensile and flexural deformations. This results in an increased toughness as reflected in the increased modulus values.

But it is observed that after the optimum filling volume of $10 \%$, further addition of fillers could not fetch a similar trend in the strength characteristics of the laminate. Maximum strength characteristics have been found to be favored by 4 plied laminate rather than its thinner 3 plied counterparts. This might be attributed to the fact that as the volume fraction of the fiber increases in the higher ' $n$ ' plied laminates enabling fiber's reinforcing capabilities taking a decisive role in controlling the laminates mechanical properties.

Besides the above observations, laminates with better load bearing capacity has been noticed in four plied than against the three plied versions probably due to better bonding and stiffness characteristics provided out of a relatively higher volume fraction of matrix material. The influence of symmetry city in balanced 4 plied laminate also cannot be over ruled here. But when it comes to Electrical properties higher di electrical strength was found for $10 \%$ of filler addition in case of both the plied laminates. On the 
other hand, minimum di electric constant was recorded against the maximum filler addition of $30 \%$, in both laminate types. This has gone as per the predicted trends. Least dissipation factor was observed for 3 plied laminate with $20 \%$ filler addition. By and large the structural properties were found to be higher for 4 plied symmetrically balanced cross plied laminate whereas majority of the di Electrical properties were found to reflect the expected trend in favor of 3 plied laminate. The role of symmetry of the laminates was not found to influence the di Electrical properties.

\section{Reference}

1. Meeks AC. Polymer, Revolutionary Materials: Technology and Economics. 1974. p. 675

2. Jeayakumari LS, Thulasiraman V, Sarojadevi M. Synthesis and characterization of cyanate epoxy composites. High Performance Polymers. 2007; 19:33-47.

3. Pearce PJ, Ennis BC, Morris CEM. Polymer comm. 1988; 29:83.

4. Lee J, Yee AF. Fracture behavior of glass bead filled epoxies, cleaning process of glass beads. Journal of Applied Polymer Science. 2001; 79:1371-83.
5. Adachi T, Osaki M, Araki W, Kwon SC. Fracture toughness of nano- and micro-spherical silica-particle filled epoxy composites. Acta Materialia. 2008; 56:2101-9.

6. Farber KT, Evans AG. Crack deflection process-I: Theory. Acta Metallurgica. 1983; 31:565-76.

7. Farber KT, Evans AG. Crack deflection process-II: Experiment. Acta Metallurgica. 1983; 31:577-84.

8. Lange FF. The interaction of a crack front with a second-phase dispersion. Philosophical Magazine. 1970; 22:983-92.

9. Green DJ, Nicholson PS, Embury J. Fracture of a brittle particulate composite: Part 2. Theoretical aspects. Journal of Materials Science. 1979; 14:1657-61.

10. Bhuvana S, Saroja Devi M. A study on the synthesis and characterization of epoxy/amine terminated amideimide-imide blends'. Applied Polymer Science. 2000; 108:2001-9.

11. Chaplin A, Hamerton I, Herman H, Mudhar AK, Shaw SJ. Studying water uptakes effects in resins based on cyanate ester/bismaleimide blends. Polymer. 2000; 41:3945-56.

12. Mathew D, Reghunadhan Nair CP, Ninan KN. Bisphenol a dicyanate -novalac epoxyblend cure characteristics, physical and mechanical properties and application in composites. Journal Applied Polymer Science. 2001; 74:1675-85. 